\title{
Diagnosis and clinical significance of parainfluenza virus infections in children
}

\author{
M. A. P. S. DOWNHAM, J. MCQUILLIN, and P. S. GARDNER \\ From the Departments of Child Health and Virology, Royal Victoria Infirmary, Newcastle upon Tyne
}

Downham, M. A. P. S., McQuillin, J., and Gardner, P. S. (1974). Archives of Disease in Childhood, 49, 8. Diagnosis and clinical significance of parainfluenza virus infections in children. The diagnosis and clinical features of parainfluenza virus infections are described in 151 children admitted to hospital over a 2-year period. Immunofluorescence was the most sensitive method of laboratory diagnosis, while virus isolation in tissue culture was more often achieved from nasopharyngeal secretions than from cough/nasal swabs. Parainfluenza viruses were responsible for approximately $9 \%$ of 1603 acute respiratory admissions. Croup was the commonest of the wide range of respiratory illnesses associated with these infections; in a series of 132 children with croup, a parainfluenza virus was identified in $42 \%$. 24 of the 151 children presented with febrile convulsions, and in a series of 209 children admitted with febrile convulsions, parainfluenza viruses were responsible for $11 \%$. 3 of the children died in hospital with their parainfluenza virus infections, and in addition there was one instance of a close association between parainfluenza virus type 3 infection and the sudden unexpected death of an infant at home. Parainfluenza virus types $4 a$ and $4 b$, which have so far rarely been identified, were isolated from 16 children.

The age distribution and seasonal patterns of the infections are described. Attention is drawn to the risks of cross-infection by parainfluenza viruses in children's wards, and the finding that virus is commonly excreted for at least a week after the onset of the illness.

It is well known that parainfluenza viruses are a major cause of acute respiratory illness in children (Chanock et al., 1958, 1963; Holzel et al., 1963, 1965). However, it was only in 1968 , when a rapid and therefore clinically relevant method of laboratory diagnosis was developed (Gardner et al., 1971), that it became possible to assess more accurately the proportion of acute respiratory admissions for which parainfluenza viruses are responsible and also the nature of the illnesses which they cause. In the 4 years from 1968 to 1972 we identified parainfluenza viruses in 226 children admitted to hospitals on Tyncside. A first clinical assessment in 75 children was made by Gardner and his colleagues in 1971. We present our further experience with 151 children in whom parainfluenza viruses were identified during the 2 years from 1 November 1970 to 31 October 1972.

In addition to presenting in more detail the incidence, clinical patterns, and laboratory diagnosis

Received 21 June 1973 of infections caused by parainfluenza virus types 1 , 2 , and 3 , we describe the illnesses associated with types $4 \mathrm{a}$ and $4 \mathrm{~b}$, which had not previously been identified in the Newcastle area, and only rarely in the country as a whole.

Parainfluenza viruses may be a cause of death from respiratory infection, and the close association in one child between parainfluenza virus type 3 infection and 'cot death' is reported. Finally, attention is drawn to the risks of cross-infection by parainfluenza viruses in children's wards.

\section{Methods}

For a number of years all children admitted with acute respiratory illnesses to hospitals in Newcastle and Gateshead have been investigated for virus infection. The clinical categories used, the methods for obtaining nasopharyngeal secretions and cough/nasal swabs, and the tissue culture techniques employed have all been described previously (Gardner et al., 1960; Gardner, 1968; Sturdy, McQuillin, and Gardner, 1969). The rapid diagnosis of parainfluenza types 1,2 , and 3 by 
immunofluorescence was described in detail by Gardner et al. in 1971 .

An immunofluorescent technique is not yet available for parainfluenza virus types $4 \mathrm{a}$ and $4 \mathrm{~b}$. These viruses were grown in tissue culture and identified by the haemadsorption neutralization test. The neutralization sera for types $4 \mathrm{a}$ and $4 \mathrm{~b}$ were supplied by the Standards Laboratory at Colindale.

Methods of virus identification in necropsy material have been described previously (Gardner, McQuillin, and Court, 1970a).

\section{Results}

\section{Laboratory diagnosis.}

Immunofluorescence compared with culture. Immunofluorescence of nasopharyngeal secretions has been established as a reliable diagnostic method for parainfluenza viruses (Gardner et al., 1971), making it possible to compare the sensitivity of immunofluorescence with that of tissue culture. Table I shows this comparison for 127* naso-

\section{TABLE I}

Results of 127 nasopharyngeal secretions examined simultaneously by immunofluorescence $(I F)$ and tissue culture (TC)

Positive by both IF and TC

Positive by IF, negative by TC

Positive by TC, negative by IF

pharyngeal secretions which were positive either by immunofluorescence or by virus isolation on tissue culture, and which were examined simultaneously by both methods.

Nasopharyngeal secretions compared with cough/nasal swabs for culture only. 134 children with parainfluenza infections had both nasopharyngeal secretions and cough/nasal swabs taken at the same time. Table II compares the tissue culture isolation results for these two methods.

Serology. 18 children in whom parainfluenza viruses were identified had acute and convalescent specimens of sera examined by the complement fixation test. Table III shows that 8 of the 18 pairs failed to show a rising titre to the identified virus. The interval between the two specimens ranged from 9 to 30 days, and the ages of these 18 children

*Of the remaining 24 cases, 16 were parainfluenza virus types $4 a$ and $4 \mathrm{~b}$, identifiable by culture only; 4 were diagnosed by isolation of virus from cough/nasal swabs only, 2 of whom did not have secretions taken; and 4 secretions, positive by immunofluorescence, were not cultured simultaneously because of lack of supply of monkey kidney cells.
TABLE II

Comparison of cough/nasal swabs (CS/NS) with nasopharyngeal secretions (NPS) in identifying parainfluenza virus infections by tissue culture in 134 children who had both types of specimen taken and cultured simultaneously

\begin{tabular}{l|c}
\hline Total cases with simultaneous CS/NS and NPS & 134 \\
Isolations from CS/NS & $98(73 \%)$ \\
Isolations from NPS & $120(90 \%)$ \\
Isolations using both methods of sampling & $124(93 \%)^{\star}$ \\
\end{tabular}

^In the 10 remaining cases virus was identified only by immunofluorescence.

TABLE III

Results of complement fixation (CF) tests on 18 pairs of sera from children in whom parainfluenza viruses had been identified

\begin{tabular}{l|c|c|c}
\hline & Rising CF titre & No rising CF titre & Total \\
\hline Parainfluenza 1 & 4 & 5 & 9 \\
Parainfluenza 3 & 6 & 3 & 9 \\
\hline Total & 10 & 8 & 18 \\
\hline
\end{tabular}

varied from 6 weeks to 4 years. There appeared to be no correlation between a rising titre and either interval or age in this small series.

Incidence. During the 2 years from the beginning of November 1970 to the end of October 1972, parainfluenza viruses were identified in 151 children admitted to hospital. Fig. 1 shows that this represents approximately $9 \%$ of the 1603 acute respiratory admissions over this period, and compares the contributions made by other viruses. These admissions are drawn from a total population of 605,000 , with a live annual birth rate of approximately 8000 .

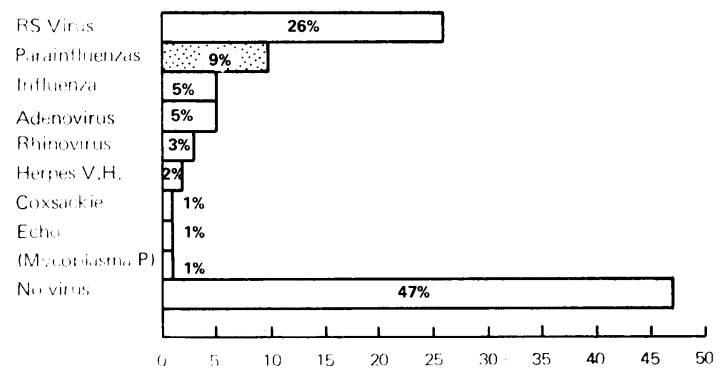

FIG. 1.-Viruses identified in 1603 children admitted with acute respiratory illness, 1970-72. $R S$, respiratory syncytial virus; Herpes V.H., Herpesvirus hominis; Mycoplasma $P$, Mycoplasma pneumoniae. 
TABLE IV

Illnesses caused by 5 different parainfluenza virus types

\begin{tabular}{|c|c|c|c|c|c|c|}
\hline & Para 1 & Para 2 & Para 3 & Para 4a & Para 4b & Total \\
\hline $\begin{array}{l}\text { Pneumonia } \\
\text { Bronchiolitis } \\
\text { Bronchitis } \\
\text { Croup } \\
\text { URIS* }\end{array}$ & $\begin{array}{r}2 \\
3 \\
9 \\
34 \\
7\end{array}$ & $\begin{array}{l}-1 \\
1 \\
8 \\
1\end{array}$ & $\begin{array}{r}8 \\
5 \\
20 \\
13 \\
23\end{array}$ & $\begin{array}{l}1 \\
1 \\
3 \\
3\end{array}$ & $\begin{array}{l}1 \\
1 \\
1 \\
1 \\
4\end{array}$ & $\begin{array}{l}12 \\
11 \\
34 \\
56 \\
38\end{array}$ \\
\hline Total & 55 & 11 & 69 & 8 & 8 & 151 \\
\hline
\end{tabular}

^URIS, upper respiratory infection syndrome.

Clinical patterns. Table IV shows the illnesses produced by the different parainfluenza virus types. Of particular importance are the ability of each virus type to produce a wide range of illnesses from a mild cold to severe pneumonia, the predominance of croup, especially among illnesses due to virus types 1 and 2, and the tendency for parainfluenza virus type 3 to be associated with lower respiratory tract illness more often than the other virus types. Types $4 \mathrm{a}$ and $4 \mathrm{~b}$ also appear to be capable of producing a wide range of respiratory illnesses.

The major part played by the parainfluenza virus group in the aetiology of croup is shown in Fig. 2,

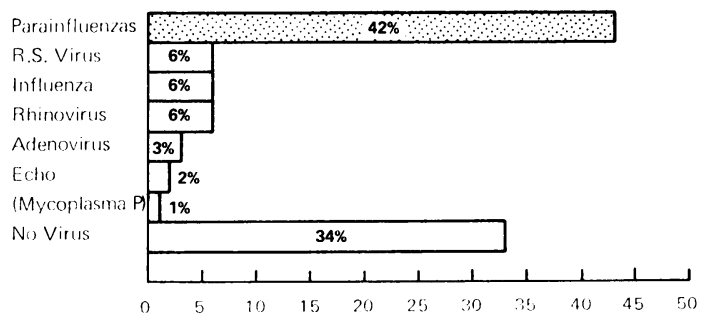

FIG. 2.-Viruses identified in 132 children admitted with croup, 1970-72. For abbreviations, see Fig. 1.

which illustrates the viruses identified in 132 children admitted consecutively with croup over the 2-year period. A parainfluenza virus was identified in $42 \%$.

Febrile convulsions were also a common presenting feature in children with parainfluenza virus infection, and occurred in 24 of the 151 children in this series. Table $\mathrm{V}$ shows the relative frequency of convulsions for the different virus types. The higher frequency of febrile convulsions among illnesses caused by type $4 \mathrm{~b}$ infections is significant $\left(x^{2}=13 \cdot 7, P<0 \cdot 0005\right)$. Of 209 children admitted consecutively with febrile convulsions over the 2-year period, parainfluenza viruses were found in $11 \%$.

Of the 151 children, 13 were noted to have a rash at the time of their parainfluenza illness (type 1,5 with rash; type 3, 8 with rash). This was a faint maculopapular eruption mainly on the trunk, lasting from 24 to 48 hours. The aetiological association between these rashes and parainfluenza virus infection remains in doubt, as the incidence of transient rashes of this kind was not established for a control series of children with febrile illnesses.

Well-marked paroxysms of coughing, often associated with vomiting and sometimes with a whoop, were noted in 11 of the 151 children. These were mostly young babies, 8 out of the 11 being under 6 months of age. In 6 of the 11 the paroxysms continued for at least 4 weeks, thus meeting the full clinical criteria for whooping cough as defined by Court, Jackson, and Knox (1953). Bordetella pertussis was not identified in any of these children.

Death. 3 children died in hospital at the time of their parainfluenza infection. All 3 had primary conditions which could have affected their immunological response. The first was a 6-month-old baby

TABLE V

Proportion of children who had febrile convulsions for each parainfluenza virus type

\begin{tabular}{l|c|c|c|c|c|c}
\hline & Para 1 & Para 2 & Para 3 & Para 4a & Para 4b & Total \\
\hline $\begin{array}{l}\text { Total illnesses } \\
\text { Febrile convulsions }\end{array}$ & $\begin{array}{c}55 \\
4(7 \%)\end{array}$ & $\begin{array}{c}11 \\
1(9 \%)\end{array}$ & $\begin{array}{c}69 \\
12(17 \%)\end{array}$ & $\begin{array}{c}8 \\
2(25 \%)\end{array}$ & $\begin{array}{c}8 \\
5(62 \%)\end{array}$ & $\begin{array}{c}151 \\
24\end{array}$ \\
\hline
\end{tabular}


who had been in hospital for 6 weeks for investigation of thymic alymphoplasia and a- $\gamma$ globulinaemia. While in the ward he developed pneumonia, and parainfluenza virus type 3 was identified in his nasopharyngeal secretions. 2 days later he died, and type 3 virus was recovered from tracheal and bronchial swabs and from both lungs at necropsy. Histology of the lungs showed a diffuse interstitial pneumonia.

The second child, aged 14 months, had been on treatment for cretinism since the age of 9 months and had had recurrent lower respiratory tract infections. Parainfluenza virus type $4 \mathrm{~b}$ was isolated from specimens taken on the day of admission with bronchiolitis, and when she died later that day, the same virus was recovered from her left lung. Lung histology showed acute bronchiolitis.

The third child was a 7-year-old girl with acute lymphoblastic leukaemia, for which she was being treated at home with methotrexate. She was admitted with pneumonia, and parainfluenza virus type 1 was identified in her nasopharyngeal secretions. The following day she died, but no necropsy examination was performed.

As well as being a cause of death in hospital, there is increasing evidence that parainfluenza viruses, in common with other respiratory viruses, may be involved in sudden unexpected infant deaths at home (Ferris et al., 1973). During this study a 3-month-old boy died in this way in association with a parainfluenza virus infection. He had been completely well when put to bed, but was found dead in his cot the next morning. At necropsy, type 3 virus was identified in tracheal and bronchial swabs and in his right lung. Histology of the lungs showed changes suggesting early bronchiolitis. 10 days before death the baby had been discharged from hospital after a week's stay for gastroenteritis. In the adjacent cubicle at that time was a child with croup due to type 3 virus.

Age. Fig. 3 shows the age distribution of children admitted to hospital with illnesses due to parainfluenza virus types 1 and 3 , and compares these with the ages of children admitted with infections due to respiratory syncytial virus and influenza A. It can be seen that parainfluenza virus type 3 illnesses have a younger age distribution than those due to type $1,50 \%$ of them occurring under the age of 1 year.

27 of the total 151 children were less than 6 months of age. The youngest child was aged 6 weeks.

It was noted that the age distribution varied considerably among the different clinical categories

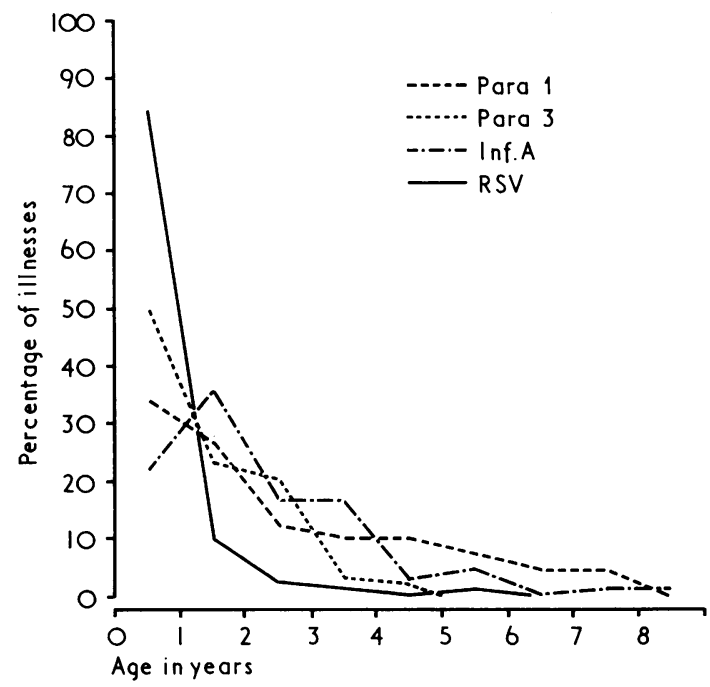

FIG. 3.-Age distribution of children admitted to hospital with illnesses due to parainfluenza virus type 1 (55 children), parainfluenza virus type 3 (69), respiratory syncytial virus (RSV) (219), and influenza $A$ virus (77).

of illness, and Fig. 4 shows the contrast between croup and bronchitis.

Seasonal patterns. Fig. 5 shows the monthly identifications over the past 5 years for each of the 5 different virus types. It is constructed from the findings of the previous study (Gardner et al., 1971)

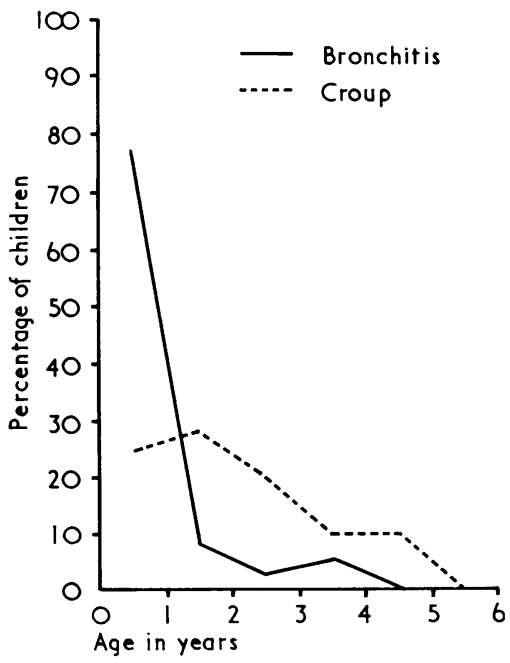

FIG. 4.-Comparison of age distribution of croup due to parainfluenza virus infection (56 children) with that of bronchitis due to parainfluenza virus infection (34 children). 


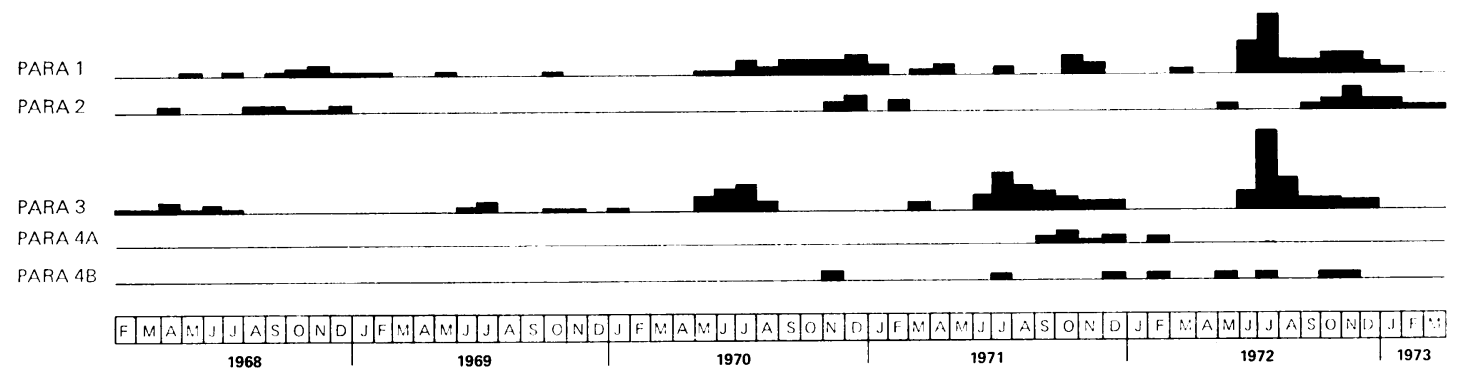

FIG. 5.-Monthly identifications of parainfluenza viruses in children in Tyneside hospitals, 1968-73.

and virus identifications made over recent months, as well as from the results of the present study. In every year a summer epidemic of parainfluenza virus type 3 infection has occurred, with the peak usually in July. Type 1 appears to follow a biennial pattern, with epidemics usually centred on the autumn of alternate years. Type 2 coincides with the type 1 fluctuations, with small outbreaks occurring in the winter of the same years. Type 4a infections were grouped together during the autumn and winter of $1971 / 72$.

Hospital cross-infection. 20 of the 151 children in the series probably acquired their parainfluenza infections in hospital, judged by the length of time they had been in hospital before developing respiratory symptoms and the availability of a known source of infection in their ward. Certainty that hospital cross-infection had occurred was not possible in every case, as the incubation period for parainfluenza infections remains unknown. From this study it seems that the incubation period lies between 2 and 10 days, but this may differ for each virus type.

The illnesses acquired by cross-infection were often severe (Table VI). The child with the immune deficiency syndrome described above, who died with parainfluenza virus type 3 pneumonia, became infected in hospital; and the baby who died

\section{TABLE VI}

Illnesses of 20 children who probably acquired parainfluenza infections in hospital

\begin{tabular}{l|c}
\hline Pneumonia & 2 \\
Bronchitis & 4 \\
Croup & 2 \\
Febrile convulsion (with URIS) & 2 \\
URIS & 10 \\
\hline Total & 20 \\
\hline
\end{tabular}

URIS, upper respiratory infection syndrome. as a 'cot death' with parainfluenza virus type 3 in his lung may well have acquired the virus directly or indirectly from the child with croup in the adjacent cubicle during his recent hospital admission. 8 of $\dot{\infty}$ the 20 cross-infections resulted in either lower 을 respiratory illness or croup, and a further 2 presented with febrile convulsions.

In 15 of these 20 cases at least one child on the same ward was known to have been excreting the same virus type at the appropriate time. In one instance the probable source of infection was the houseman, from whom the virus was isolated at the time of a severe cold, and who had himself probably acquired his infection from a child on an adjacent ward. In a further 2 instances, carriage by staff who had been in contact with infected children on other wards was probable, though specimens from suspected carriers were unfortunately not obtained. In the remaining two instances the source of the cross-infection was not identified.

Duration of infectivity. In 30 children with parainfluenza virus infections, second and sometimes third specimens of nasopharyngeal secretions were obtained at times ranging from 3 to 17 days after the onset of the illness. 41 follow-up specimens were obtained from these 30 children and virus antigen was still present in 28 specimens. Table VII shows the interval in days since the onset of the illness for positive and negative follow-up specimens for parainfluenza virus types 1,3 , and $4 a$. Follow-up secretions were not obtained in any type 2 N or type $4 \mathrm{~b}$ illnesses. The results suggest that virus $N$ excretion in parainfluenza virus illnesses commonly N persists for at least a week after the onset of the illness, and sometimes for as long as 16 days.

\section{Discussion}

The reliability of rapid diagnosis of parainfluenza infections by direct immunofluorescence, using cells from nasopharyngeal secretions, has already been 
TABLE VII

Results of follow-up secretions, showing interval between their collection and onset of illness

\begin{tabular}{l|c|c|c|c|c|c}
\hline & \multicolumn{2}{|c|}{ Positive follow-up secretions } & \multicolumn{3}{c}{ Negative follow-up secretions } \\
\cline { 2 - 7 } & No. of secretions & $\begin{array}{c}\text { Mean interval } \\
\text { (dy) }\end{array}$ & $\begin{array}{c}\text { Range } \\
\text { (dy) }\end{array}$ & No. of secretions & $\begin{array}{c}\text { Mean interval } \\
\text { (dy) }\end{array}$ & $\begin{array}{c}\text { Range } \\
\text { (dy) }\end{array}$ \\
\hline Para 1 & 7 & $7 \cdot 0$ & $3-12$ & 3 & $11 \cdot 0$ & $9 \cdot 6$ \\
Para 3 & 20 & $8 \cdot 9$ & $3-16$ & 7 & $5-16$ \\
Para 4a & 1 & 5 & 5 & 3 & $14 \cdot 3$ & $12-17$ \\
\hline
\end{tabular}

established (Gardner et al., 1971). The results of this study confirm our confidence in the method, and in addition show that it is a more sensitive method of diagnosis than tissue culture (Table I). This increased sensitivity is chiefly attributable to two factors. As in the case of respiratory syncytial virus (Gardner, McQuillin and McGuckin, 1970b) and influenza A (Brocklebank et al., 1972), immunofluorescence can be shown for a longer time in cells of nasopharyngeal secretion than can virus by culture. 6 of the 11 secretions shown in Table I, which were negative on culture but positive by immunofluorescence, were taken at least 7 days after the onset of symptoms. Secondly, when a dual virus infection is present, one of the two viruses may sometimes fail to survive the competition in tissue culture, while its detection by immunofluorescence remains unaffected. Of the same 11 secretions in Table I, 3 yielded a second virus on tissue culture (respiratory syncytial virus, 1 ; adenovirus type 5,1 ; Coxsackie virus type $A 9,1$ ).

Nasopharyngeal secretions also show a clear advantage over cough/nasal swabs when culture only is considered, yielding a $17 \%$ higher isolation rate. This is similar to findings for culture of respiratory syncytial virus (Sturdy et al., 1969). If cough/nasal swabs only had been taken without obtaining simultaneously a specimen of nasopharyngeal secretions, 26 isolations made from those secretions would have been missed; while if nasopharyngeal secretions had been used alone, only 4 isolations by tissue culture would have escaped detection. However, 2 of these 4 swabs yielded parainfluenza virus type $4 \mathrm{~b}$; it is possible that the cough/nasal swab remains a more reliable method of identifying type $4 \mathrm{~b}$ infections, but no firm conclusion can be drawn until larger numbers of this virus type have been identified.

Serological diagnosis of parainfluenza virus infections by the complement fixation test seems to be not only slow and inconvenient for both physician and patient, but also relatively insensitive.

Parainfluenza viruses as a group are second only to respiratory syncytial virus among the viruses responsible for the admission of children to hospital with acute respiratory illness. We estimate that on Tyneside at least one child in every 100 is admitted with a parainfluenza infection during the first 5 years of life. This compares with a figure of approximately one child in every 30 for respiratory syncytial virus, but these illnesses occur predominantly during the first year of life.

The features of the illnesses in this series agree broadly with previous impressions (Van der Veen and Smeur, 1961; Chanock et al., 1963; Gardner et al., 1971). The growing realization of the importance of the parainfluenza group in the aetiology of croup is emphasized by the fact that one or other parainfluenza virus type was identified in $42 \%$ of the 132 children with croup in this series. This compares with $35 \%$ of 94 cases over the previous period (Gardner et al., 1971), and the figure of $29 \%$ quoted by Chanock et al. in 1963.

Parainfluenza virus type 3 infection causes lower respiratory tract illnesses more often than the other virus types, confirming previous findings; and it was found in this study that this tendency could not be completely explained by the younger age distribution for type 3 virus.

Febrile convulsions have not previously been stressed as a frequent cause of hospital admission in parainfluenza infections. Virus investigation, especially by the rapid immunofluorescent method, seems worth while as a routine measure in children with febrile convulsions, and not only in those with frank respiratory signs but also where the nature of the underlying illness is in doubt, as respiratory symptoms were minimal in some of the 24 children with convulsions in this series. Wallace and Zealley (1970) found that children in whom a virus infection was identified at the time of a febrile convulsion suffered a greater incidence of subsequent permanent neurological damage than children with febrile convulsions in whom virological investigation was negative. We hope to throw further light on the possible prognostic significance of virus 
identification in children with febrile convulsions by a follow-up study of the 209 children admitted with febrile convulsions during this 2-year period.

It is possible that some viruses are more liable than others to induce convulsion, such as parainfluenza $4 \mathrm{~b}$ (Table $\mathrm{V}$ ), or influenza $\mathrm{A}$, which was found to be associated with febrile convulsions in $40 \%$ of children admitted to hospital with this infection (Brocklebank et al., 1972). It seems more likely, however, that this is a biased impression gained by focusing attention on children admitted to hospital. Only when incidence and patterns of illness are better understood for the community as a whole will it become possible to assess the true convulsion risk for each type of virus.

The 16 parainfluenza $4 a$ and $4 b$ infections were the first identifications of these viruses on Tyneside, and during this 2-year period only 5 other identifications were reported from the country as a whole, 2 type $4 \mathrm{a}$ and 3 type $4 \mathrm{~b}$. However, Sylvia Gardner's serological survey (Gardner, 1969), suggests that infection with these agents is common in early childhood. The rarity with which they have been identified to date may be due to the technical difficulties involved, and in particular the fact that the immunofluorescent method is still not available for these types. Alternatively, it may be that the majority of these infections produce illnesses too mild for hospital admission.

Although it seems possible that parainfluenza viruses may produce an illness in young babies similar to or indistinguishable from that associated with Bord. pertussis, we have pointed out elsewhere that as yet we have no firm evidence of their aetiological association with such illnesses (Sturdy, Court, and Gardner, 1971).

The tendency for parainfluenza virus type 1 to occur in biennial epidemics has been described by others (Public Health Laboratory Service Report, 1973; Glezen and Denny, 1973), but the simultaneous periodicity of parainfluenza virus type 2 infections, shown in Fig. 5, is a new finding. Though this may be a coincidence, it is possible that it reflects similar patterns of childhood immunity or of optimal environmental conditions for the two virus types. However, Glezen and Denny (1973) reported that in North Carolina parainfluenza virus type 1 and type 2 infections tended to alternate, and not to appear synchronously.

Virological investigation of children developing respiratory symptoms after admission to hospital has shown a considerable risk of cross-infection by parainfluenza viruses, and we may well find that this problem is greater than our figures suggest. The illnesses acquired are often severe, and this is especially so for children suffering from primary debilitating conditions. The problems of cross-? infection in children's wards, not only for para- $\overrightarrow{\vec{B}}$ influenza viruses, but also for respiratory syncytial virus and influenza $A$, have recently been discussed in a separate article (Gardner et al., 1973) that suggested ways to reduce the risk. The present study has shown that parainfluenza viruses can be excreted for at least a week and sometimes two weeks of after the onset of symptoms, suggesting that these $\vec{\circ}$ children should be regarded as infectious for this length of time, even though their symptoms may have become minimal. Carriage by staff occurred in at least one instance in this study, and similar observations have been made for respiratory syncytial virus (Ditchburn et al., 1971). We are currently studying the part played by staff, parents, $\infty$ and visitors in hospital cross-infection by respiratory $ᄋ$ viruses.

We are indebted to the medical and nursing staff of the children's wards in Newcastle and Gateshead for their continued co-operation, and are grateful to the technicians in the Department of Virology. We acknowledge with thanks the continued support of the $\vec{\theta}$ Medical Research Council and the Scientific and $I$ Research Sub-Committees, both of the Group and of the Regional Hospital Board.

\section{REFERENCES}

Brocklebank, J. T., Court, S. D. M., McQuillin, J., and Gardner, P, S. (1972). Influenza-A infection in children. Lancet, 2, 497. Chanock, R. M., Parrott, R. H., Cook, K., Andrews, B. E., Bell, J. A., Reichelderfer, T., Kapikian, A. Z., Mastrota, F. M., and Huebner, R. J. (1958). Newly recognized myxovirus from children with respiratory disease. New England fournal of Medicine, 258, 207.

Chanock, R. M., Parrott, R. H., Johnson, K. M., Kapikian, A. Z., and Bell, J. A. (1963). Myxovirus: parainfluenza. American Review of Respiratory Diseases, 88, Suppl. 152.

Court, D., Jackson, H., and Knox, G. (1953). The recognition of whooping-cough. Lancet, 2, 1057.

Ditchburn, R. K., McQuillin, J., Gardner, P. S., and Court, S. D. M. (1971). Respiratory syncytial virus in hospital cross-infection. British Medical fournal, 3, 671.

Ferris, J. A. J., Aherne, W. A., Locke, W. S., McQuillin, J., and Gardner, P. S. (1973). Sudden and unexpected deaths in infants: histology and virology. British Medical fournal, 2, 439.

Gardner, P. S. (1968). Virus infection and respiratory disease of childhood. Archives of Disease in Childhood, 43, 629.

Gardner, P. S., Court, S. D. M., Brocklebank, J. T., Downham, M. I A. P. S., and Weightman, D. (1973). Virus cross-infection in paediatric wards. British Medical fournal, 2, 571.

Gardner, P. S., McQuillin, J., and Court, S. D. M. (1970a). Speculation on pathogenesis in death from respiratory syncytial virus infection. British Medical fournal, 1, 327.

Gardner, P. S., McQuillin, J., and McGuckin, R. (1970b). The late detection of respiratory syncytial virus in cells of respiratory tract by immunofluorescence. Fournal of Hygiene, 68, 575.

Gardner, P. S., McQuillin, J., McGuckin, R., and Ditchburn, R. K. 穴 (1971). Observations on clinical and immunofluorescent diagnosis of parainfluenza virus infections. British Medical fournal, $2,7$.

Gardner, P. S., Stanfield, J. P., Wright, A. E., Court, S. D. M., and Green, C. A. (1960). Viruses, bacteria, and respiratory disease in children. British Medical fournal, 1, 1077.

Gardner, S. D. (1969). The isolation of parainfluenza 4 subtypes A and $B$ in England and serological studies of their prevalence. fournal of Hygiene, 67, 545. 
Glezen, W. P., and Denny, F. W. (1973). Epidemiology of acute lower respiratory disease in children. New England fournal of Medicine, 288, 498.

Holzel, A., Parker, L., Patterson, W. H., Cartmel, D., White, L. L. R., Purdy, R., Thompson, K. M., and Tobin, J. O'H. (1965) Virus isolations from throats of children admitted to hospital with respiratory and other diseases, Manchester, 1962-64. British Medical fournal, 1, 614.

Holzel, A., Parker, L., Patterson, W. H., White, L. L. R., Thompson, K. M., and Tobin, J. O'H. (1963). The isolation of respiratory syncytial virus from children with acute respiratory disease. Lancet, 1, 295.

Public Health Laboratory Service Report (1973). Parainfluenza type 1 virus. British Medical fournal, 1, 183.

Sturdy, P. M., Court, S. D. M., and Gardner, P. S. (1971). Viruses and whooping-cough. Lancet, 2, 978.
Sturdy, P. M., McQuillin, J., and Gardner, P. S. (1969). A comparative study of methods for the diagnosis of respiratory virus infections in childhood. Fournal of Hygiene, 67, 659.

Van der Veen, J., and Smeur, F. A. A. M. (1961). Infections with parainfluenza viruses in children with respiratory illness in Holland. American Fournal of Hygiene, 74, 326.

Wallace, S. J., and Zealley, H. (1970). Neurological, electroencephalographic, and virological findings in febrile children. Archives of Disease in Childhood, 45, 611.

Correspondence to Dr. M. A. P. S. Downham, Department of Virology, Royal Victoria Infirmary, Queen Victoria Road, Newcastle upon Tyne NE1 4LP. 